\title{
O ÉDIPO NA MULHER E SUA EXTRAPOLAÇÃO A TODOS O SER
}

\section{THE OEDIPUS THE WOMAN AND HER BEING ALL EXTRAPOLATION}

\author{
Gustavo Capobianco Volaco*
}

\begin{abstract}
RESUMO
O presente artigo pretende articular o complexo de Édipo às questões prototípicas da feminilidade usando como contraponto a organização dita masculina para desembocar na ideia, formulada por Lacan em seus últimos seminários de que um fim de análise coloca o sujeito nesse campo da não-totalidade e, por isso mesmo, o aproxima desse ser, que não existe. Nesse percurso que poderíamos dizer cartesiano,o autor utilizará algumas referências literárias para a explanação como forma de dar suporte e aporte a teoria psicanalítica.
\end{abstract}

Palavras chave: Complexo de Édipo. Feminilidade. Fim de Análise.

\begin{abstract}
This article articulates the Oedipus complex issues using prototypical femininity as a counterpoint to the organization dictates male culminate in the idea, formulated by Lacan in his later seminars that a close analysis places the subject in the field of non-whole and therefore, the approach of this being that does not exist. In this way we could say Cartesian, the author uses a few literary references to the explanation as a way to support and contribution to psychoanalytic theory.
\end{abstract}

Keywords: Oedipus complex. Femininity. End of analysis.

"Uma forma de fala: o menor pelo maior". James Joyce ${ }^{1}$

\footnotetext{
" Psicanalista, graduado em psicologia pela PUCPR, especialista em literatura brasileira e história nacional pela UTFRP, mestre em letras pela UFPR e professor e coordenador do curso de Psicologia do Centro Universitário Facvest. Fone: 498896 1919. E-mail: gustavovolaco@hotmail.com

${ }^{1}$ JOYCE, James. Giacomo Joyce. São Paulo: Iluminuras, 1999, p. 25.
} 
Foi, é, e me parece que sempre será - mesmo que acumulemos saber a respeito - perturbador identificar que, inevitavelmente, somos efeitos daquilo que Freud, a muito custo e trabalho desencavou e nomeou como Complexo de Édipo ${ }^{2}$. Dito de outra maneira e mais implicativa para nós todos: quem, do mais ilustrado ao mais ignorante, não se espanta, não se aturde ${ }^{3}$ em perceber, em $\mathrm{si}^{4}$, que Jocasta é mesmo um norte de nosso desejo e que Laio ${ }^{5}$, morto na encruzilhada desse complexo, sua outra medida?

Mas isso seria para todos, ou seja, seria o Édipo Universal ${ }^{6}$ e nos restaria amarmos nossas mães e odiarmos nossos pais derivando dessa $\mathrm{Lei}^{7}$ outras leis? Nem tudo são flores, meus caros, e se a clínica atesta essa organização nos ditos machos, ela - que é feita da verdade que fala naquilo que se escuta daquilo que se $\operatorname{diz}^{8}$ - complexiza ${ }^{9}$ o que já era com-

\footnotetext{
${ }^{2}$ Freud usa pela primeira vez a expressão Complexo de Édipo em 1910, no texto por nós conhecido como Um Tipo Especial de Escolha de Objeto Feita pelos Homens, in Obras Completas. Rio de Janeiro, Imago, 1980, p. 154. Ele, é claro, já havia feito várias referências ao mito de Sófocles e se vasculharmos sua obra já a encontraremos numa carta a seu amigo Fliess datada de 1897. Ver, sobre isso, FREUD, Sigmund. A Correspondência Completa de Sigmund Freud para Wilhelm Fliess - 1887- 1904. Rio de Janeiro: Imago, 1986.

${ }^{3}$ Lacan escreve um texto que se chama o Aturdito - e não o aturdido, como seria o comum - para expressar, já a partir de seu título, o atordôo que produz a fala, a linguagem, sobre o ser-humano. LACAN, Jacques. O Aturdito, in Outros Escritos. Rio de Janeiro: Jorge Zahar Editor, 2003, p. 448 - 497.

${ }^{4}$ Me parece que esse em si é uma das grandes descobertas freudianas. Ele traz a "Nau dos Loucos" (FOUCAULT, Michel. A História da Loucura na Idade Clássica. São Paulo: Perspectiva, 1993, p. 09) para dentro de nossas fronteiras.

${ }^{5}$ Jocasta foi a mãe de Édipo, com a qual se deitou produzindo três filhos. Laio foi seu pai, que num entrevero acerca de quem deveria passar primeiro por certa encruzilhada, é morto pelas mãos do filho. Ver SÓFOCLES. Édipo Rei, in A Trilogia Tebana. Rio de Janeiro: Jorge Zahar Editor, 1995.

${ }^{6}$ Essa pergunta, a da universalidade ou não do Édipo já fez Escola em mais de um lugar e não irei aqui listá-las. Apenas me parece digno de nota que essa estrutura triádica, para não dizer tretrádica, se levamos em consideração o falo enquanto significante da falta, seja lá em que cultura for aparece de forma iniludível e apenas mudam-se, quando é o caso, os nomes dos personagens. Para esta estruturação ver O Seminário As Formações do Inconsciente, livro 5. Rio de Janeiro: Jorge Zahar Editor, 1999, p. 185- - 221. ${ }^{7}$ Lacan faz uma diferenciação nítida entre a Lei, escrita com letra maiúscula e a lei, grafada com minúscula. A primeira designa o desejo e a segunda as voltas da demanda. Para quem quiser mais informações a respeito, recomendo uma revista de psicanálise intitulada Palavração, subtítulo A Lei e a lei. Curitiba: Biblioteca Freudiana de Curitiba, 1994.

${ }^{8}$ Essa frase é uma corruptela de outra, de autoria de Lacan, que escreve assim neste texto que já fiz referência aqui anteriormente (O Aturdito): "Que se diga fica esquecido por trás do que se diz em o que se ouve" (p. 448). A idéia não foi a mimese, mas evocar o que uma frase assim, tão enigmática, pode comportar, que, no caso da minha, pode assim ser decifrada: uma verdade se diz no dito comum mas ela só é ouvida quando o analista, por seu lugar específico, a pontua. Para quem quiser mais informações sobre esse conceito de verdade pode se reportar ao texto Televisão, de Jacques Lacan. Outros Escritos. Rio de janeiro: Jorge Zahar Editor, 2003, p. 508.

${ }^{9}$ A idéia de complexo em Freud é essa mesma: um entremeado de relações que formam um feixe indeslindável.
}

plexo nesse campo chamado por mais de um poeta de o continente obscuro. Explico-me parafraseando Freud: para uma mulher é necessário uma volta a mais naquilo que para o homem se apresenta de forma retilínea: ela, uma mulher, terá de trocar de objeto se escolhe o caminho da feminilidade ${ }^{10}$ e sairá, estamos ainda nessa espécie de labirinto prático-teórico, devotando seu amor àquele que antes fora marcado a ferro e fogo pelo ódio ${ }^{11}$.

E se saímos dele, do labirinto, digo, o que herdamos? Mais problematizações apontam no horizonte, pois se eles, homens, recebem o legado que o mestre vienense denominou supereu ${ }^{12}$ ela, a mulher - que deve sempre ser contada uma a uma, por não ser partidária do universal ${ }^{13}$ - e Freud é duro nessa constatação, não o possui ${ }^{14}$. Seria ela, por essa razão, uma fora-da-lei? Um pouco, e não é a toa que Lacan a designou de não-toda ${ }^{15}$ para esclarecer esse

\footnotetext{
${ }^{10}$ Freud apresenta três saídas ao Édipo na menina: a neurose, a homossexualidade e a feminilidade. Ver Novas Conferências Introdutórias a Psicanálise, A Feminilidade, in Obras Completas. Rio de Janeiro, Imago, 1980, p 155.

${ }^{11}$ Essa idéia da troca de objeto - e a controversa mudança de zona erógena está também no texto que listamos acima só que na página 147.

${ }^{12}$ Literalmente: "O ideal do ego é o herdeiro do complexo de Édipo" O Ego e o Id, in Obras Completas. Rio de Janeiro, Imago, 1980, p 51. Mas como assim ideal do ego? E você não disse supereu? Poderia me perguntar um leitor atento. Pois é, Freud por algumas vezes usa no lugar de supereu esse outro conceito que se chama ideal do eu, que aparentemente se confundem mas são amplamente distintos. Ver, por exemplo, as definições de Lacan a esse respeito no Escritos Técnicos de Freud. Rio de Janeiro: Jorge Zahar Editor, 1986, p. 152 - 167. E o eu, em supereu? Freud, esclareço, nunca usou uma terminologia latina para designar um conceito - como fazem os juristas, por exemplo - e Isso, em alemão Es, Eu, Ich, e Uberich, Supereu, foram as palavras que ele usava correntemente. Quando suas obras passaram a ser traduzidas para o inglês, seus tradutores, principalmente Ernst Jones, achou de bom tom dar um ar científico àquilo que era palavra corrente na língua alemã. Coisas de discípulo!

(Nota da nota: retomando para uma aula o esquema $\mathrm{R}$ de Lacan, que está no difícil texto De Uma Questão Preliminar a Todo Tratamento Possível da Psicose, in Escritos. Rio de Janeiro: JZE, 1998; pude notar que, de uma certa maneira Ideal do Eu e Supereu, de fato, se confundem. Como? Pois não é que ao mesmo tempo em que um pai interdita o incesto delineia um ideal a ser seguido? Ao menos é isso que se vê claramente na aresta inferior esquerda do esquema supracitado.)

${ }^{13}$ Ver sobre esse assunto o seminário de Lacan, Mais Ainda, principalmente na aula intitulada Carta de Almor. Rio de Janeiro: Jorge Zahar Editor, 1985, p. $105-120$.

${ }^{14}$ Sugiro que, para entender o que afirma Freud de forma tão peremptória se essas linhas que escrevo não forem suficientes, que se dirija ao texto A Dissolução do Complexo de Édipo, in Obras Completas. Imago: Rio de Janeiro: 1986.

${ }^{15}$ Lacan lança mão de formulas matemáticas para explicar isso que se passa no campo das mulheres. É um tema complexo e não vou agora poder me estender sobre ele e por isso deixo aqui três referencias que podem servir de auxílio. A primeira é o seminário de Lacan, já falei dele aqui nessas notas, que se chama Mais, Ainda. A segunda é um texto meu que tenta explicar o porquê de outra afirmação retumbante de Lacan, "a relação sexual não existe", e que se chama A Derissão da Esfera ou A Relação Sexual Não Existe
} 
ponto que, como eu já disse aqui, é obscuro. Mas por ser noite fecharíamos os olhos? Nisso abandono o rei de Tebas e seus broches de ouro ${ }^{16}$ e reacendo o lume para ver o que nas trevas se esconde ${ }^{17}$ e por isso retomo de forma mais branda:

O menino, voltado para a mãe e mal-dizendo seu pai, se quer abandonar as fraldas e sair da barafunda levará no bolso e lei internalizada ${ }^{18}$. Carregará consigo o interdito: "não te deitarás com tua mãe"; e o inter-dito: "por isso gozarás das outras mulheres". Mas e a menina? É fato que ela deixa o cueiro - nos melhores $\operatorname{casos}^{19}$ - mas, para com suas pernas, entrar aonde? Freud é peremptório: para entrar naquilo que o menino abandonou ${ }^{20}$. Ela terá, digo uma vez mais, se desejar, bem-dizer aquele que era seu rival e dedicar sua inimizade àquela que outrora era pura ternura e meiguice. E recebe o que em troca?

Eis o resultado: se o menino, virando homem recebe o imperativo categórico ${ }^{21}$ "aqui não, mas lá, goze! ${ }^{22}$ ", a menina, ao desabrochar recebe... percebem o problema lógico? Se há, e há, para ela interdição do incesto, não há, e não há, para ela a inter-dição, o indicativo de onde ela poderia fixar seu gozo. É isso que Lacan levantará na sua terceira ida a Roma ${ }^{23}$ nessa apropriação profícua que faz do nó

Pode ser encontrado em www.letra-psicanálise.com. Se isso ainda não ajudar, talvez essa frase que qualquer um já ouviu possa servir de entrada nesse tema espinhoso: a mulher é aquela que diz: "Tudo, mais isso não" (LACAN, Jacques. O Sinthoma. Rio de Janeiro: Jorge Zahar Editor, 2009, p. 37.)

${ }^{16}$ Édipo, depois de perceber em qual enredo estava vivendo, fura seus olhos com os broches de ouro de sua mãe. A Trilogia Tebana. Rio de Janeiro: Jorge Zahar Editor, 1995, p. 86.

${ }^{17}$ Flectere si nequeo súperos, Acheronta movebo, frase do poeta Virgílio assim traduzida por Freud em sua $A$ Interpretação dos Sonhos: "Se não posso dobrar os poderes supremos, moverei as regiões infernais". in Obras Completas, vol. IV, p. 550

${ }^{18}$ Ver a nota 11 - primeiro trecho - e aproveitar para ler o texto o Ego e $o$ Id inteiro para entender aquilo que Freud chama de internalização ou introjeção, conceitos que foram retomados por Melanie Klein mas acabaram por adquirir outro estatuto.

${ }^{19}$ Nota 9.

${ }^{20}$ FREUD, Sigmund. A Dissolução do Complexo de Édipo, in Obras Completas. Imago: Rio de Janeiro: 1986, p. 221.

${ }^{21}$ Freud usa mesmo esse termo kantiano para designar o imperativo do supereu. Em o Ego e o ID, p. 98.

${ }^{22}$ Sobre esse ponto é interessante a aula de 16 de junho de 1971 onde Lacan, no seminário De Um Discurso de Que Não Seria do Semblante, dedica algumas linhas. Rio de Janeiro: Jorge Zahar Editor, 2009, p. 166.

${ }^{23}$ Trata-se, mesmo da terceira vez que Lacan fala em Roma: a primeira foi vinte e um anos antes, com seu Discurso de Roma, como forma de introduzir o relatório Função e Campo da Fala e da Linguagem em Psicanálise, respectivamente em Outros Escritos. Rio de Janeiro: JZE, 2003 e Escritos. Rio de Janeiro: JZE, 1998. A segunda vez que ele fala na capital italiana é numa entrevista que dá a imprensa em 29 de Outubro de 1974 no Centre da família Borromeu ${ }^{24}$. Vejamos: na interseção entre Imaginário e Simbólico ele põe o sentido. Nada mais justo pois sabemos bem que basta aumentá-lo, o sentido, digo, para produzir isso que se chama desde Freud inibição ${ }^{25}$. E entre o Simbólico e o Real? Aí será proposto albergar o gozo fálico e seu avanço em sentido levógiro ${ }^{26}$ produzirá aquilo que chamamos sintoma e já se percebe também a justeza de tal proposição, pois não será esse excesso de bedeutung ${ }^{27}$ aquilo que nos produz isso que chamamos de sinto-mal? Mas ainda falta essa última interseção que é nominalmente esse entre-trecho que congrega Real e Imaginário e onde o mestre parisiense situará o insituável, vale dizer, o Gozo Outro ${ }^{28}$.

Pois bem, feito esse avanço deixo 1974 - por enquanto - e recuo no tempo alguns meses até a fatídica data de 13 de março de $1973^{29}$. O que se dá a ler nessa data? Que a mulher, da direita para esquerda, se refere ao falo mas, não somente, não-

Culturel Français, portanto dois dias antes dessa conferência. Infelizmente este texto está ainda inédito ao grande público de língua portuguesa.

24 "Jacques Lacan empresta do matemático Guilbaut o nó que servia aliás como brasão à família dos Borromeus no século XV". JEANVOINE, Michel. Nó e Enodamento Borromeano, in Dicionário de Psicanálise Freud \& Lacan, vol. 1. Salvador: Ágalma, 1994.

${ }^{25}$ Ver o texto de Freud chamado Inibições, Sintoma e Angústia, mal traduzido para o português como Inibições, Sintoma e Ansiedade. In Obras Completas, vol. 14.

${ }^{26}$ Vocês irão encontrar de tempos em tempos essa nomenclatura para designar os movimentos possíveis dos nós e mais esta outra: destrogiria, que querem dizer, numa aproximação possível, respectivamente: no sentido horário e no sentido anti-horário.

${ }^{27}$ Num seminário ainda inédito Lacan retomará seu texto A Significação do Falo, para dizer que só há uma bedeutung (significação), a do falo, o que torna tautológico o título daquele escrito. Vocês poderiam encontrar isso no seminário 25, O Momento de Concluir, mas ele ainda não foi publicado. ${ }^{28}$ É assim a figuração dita acima:

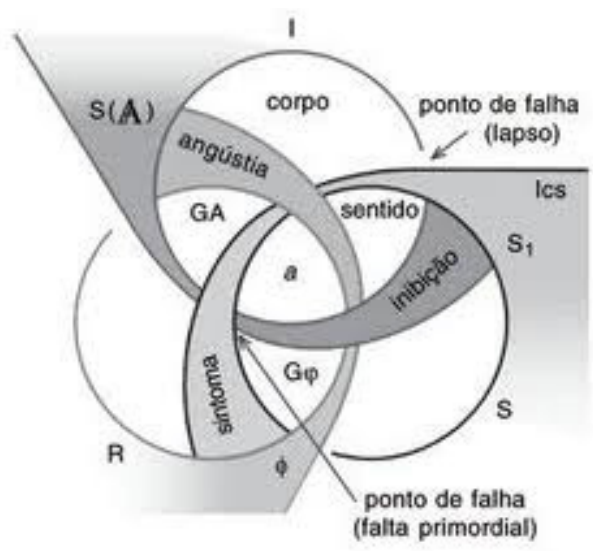

29 Dia, mês e ano da aula VII do seminário Encore, onde Lacan estabelece aquilo que será daí em diante chamado de fórmulas quânticas da sexuação. 
totalmente ${ }^{30}$, pois para ela, se há esse significante fálico, o falo propriamente dito se mostra, sempre, insuficiente para dizê-la de uma forma definitiva. Ou seja, se ela pode gozar a partir do significante unificador, para ela um Outro campo está aberto, daí a nomeação justíssima de Gozo Outro: um gozo que é alter em relação àquele que dita uma certa regra.

É com isso que a mulher, que não-existe, terá de se haver e é por isso, que ela, constantemente, preferirá o caminho da histeria ${ }^{31}$ por não suportá-la e almejar aquilo que até hoje ainda se escuta de suas bocas: todos somos iguais. Pura bobagem, diga-se de passagem pois não apenas o corpo nega tal lema como essa inscrição da não-totalidade lhes arrancará constantemente esse cajado que lhes consola ${ }^{32}$. Por quê? Insisto: porque o falo não lhe diz toda. Pode lutar contra isso o tempo que quiser, não importa, essa verdade sempre lhe retornará e se fará ouvir. Lhe habita um gozo que, como eu já disse, não foi dito no inter por seu pai e nenhum ser no mundo lhe poderá ditar. Desvantagem?

De forma alguma e, para exemplificá-la - essa não-desvantagem - e talvez calar as feministas de plantão, evoco um texto de Samuel Langhorne, mais conhecido entre nós por Mark Twain, num belíssimo conto que ele intitula "O Diário de Adão e Eva" 33 que começa assim: "Eu devia lembrar-me de que ela é muito jovem, uma criança realmente, e fazer-lhe concessões... Vejo-a curiosa, vivacíssima e cheia de avidez. O mundo the aparece como prodígio, maravilha, mistério, encantamento. A alegria a exalta, desde que encontre uma flor desconhecida; não pára de a acariciar, de a admirar, de a respirar, de lhe falar dirigindo-lhe mil nomezinhos ridículos." Esse, dá para notar, é Adão descrevendo Eva e, por uma ou mais duas páginas seguirá nesta toada. Apesar de engraçado não é isso o que mais importa neste mo-

\footnotetext{
30 "Vocês tem a inscrição da parte mulher dos seres falantes. A todo ser falante (...) é permitido inscrever-se nesta parte. Se ele se inscreve nela, não permitirá nenhuma universalidade, será não-todo, no que tem a opção de se colocar na $\phi x$ ou bem não estar nela" (LACAN, Jacques. Mais Ainda. Rio de Janeiro: JZE, 1985, p. 107). Tanto para esta nota, como para a anterior e para aquela de número 14 indico, uma vez mais, o reporte ao meu texto $A$ Derissáo da Esfera ou A Relação Sexual Não Existe.

${ }^{31}$ Ver nota 9. E mais essa interessante definição lacaniana para a histeria: "bancar o homem", que está nesse seminário que acima indicamos, à página 114.

${ }^{32}$ Referência a Bíblia, Salmos 23:4: "Porque tu estás comigo; a tua vara e o teu cajado me consolam.” Tradução de João Ferreira de Almeida. Rio de Janeiro: Imprensa Bíblica Brasileira, 1981.

33 TWAIN, Mark. Contos. São Paulo: 1985.
}

mento. O que importa é esse "mil nomezinhos ridículos" que Adão a ouve dar e mais isso, já na parte, em teoria, escrita por Eva: "encarreguei-me de todo o trabalho de designar as coisas." E um pouco mais adiante: "Quando enxergamos (ele e ela) uma nova criatura, dou-lhe um nome (...)"34 e chega por que aquilo que por esse escritor quero destacar já está aí.

Mas antes, uma passada pela Bíblia: Genesis, 2, 18: "Havendo pois o senhor Deus formado da terra todo animal do campo e toda a ave dos céus, os trouxe a Adão para este ver como lhes chamaria: e tudo o que Adão chamou a toda a alma vivente, isso foi seu nome", vale dizer, e me dirijo ao término dessa apresentação para abrir espaço para discutirmos, ele Adão, nomeia as coisas desde um mandamento, desde Deus, desde esse ao-menos-um ${ }^{35}$ que não é castrado, ou seja, o onipotente portador do falo. E Eva, nesse conto de Mark Twain? É Isso que me delicia: ela, por ser não-toda, por não ser-nãotoda -partidária-do-falo-todo-poderoso-de-Deus ${ }^{36}$, pode, se se permite, nomear as coisas que a cercam de uma forma inédita, nunca vista e nem pré-vista. Ela, essa Eva - do hebraico Cheva $=\mathrm{Vida}^{37}$ - pode por em cena a Vida ${ }^{38}$. Voltando para, como disse que faria, para 1974: onde situar na cadeia borromeana ${ }^{39}$ a vida? Nada mais que no seu devido lugar: no Real $^{40}$. E esse Gozo Outro? Bem, se ele avança sobre o corpo produzirá angústia e se recua, entra na vida lhe dando o verdadeiro estatuto: o de impossível. Impossível viver? É claro que não! Impossível dizêla - a Vida - toda. E não é que é para isso que uma análise pode servir? Pronto, cheguei onde queria: aquilo que seria puro apanágio da mulher deixa de sê-lo para abrir-se a quem puder suportá-lo.

Submissão: 10/08/2013

Aprovação: 08/2014

\footnotetext{
${ }^{34}$ Páginas 71 e 76 , respectivamente.

${ }^{35}$ Esse ao-menos-um, para ser claro num mar que sei bem, não está muito límpido, é a exceção que faz a regra.

${ }^{36}$ Escrevo tudo isso junto para enfatizar que se trata aí, mesmo, de uma palavra composta.

${ }^{37}$ Nas notas escritas por Bernardina da Silveira, última tradutora de Ulisses até o presente momento, de James Joyce, assim a estabelece: Heva, do hebraico Cheva=Vida. SILVEIRA, Bernardina da. Notas a Ulisses de James Joyce, in Ulisses. Rio de Janeiro: Alfaguara, 2007.

${ }^{38}$ Que Lacan situará no campo do Real. Ver A Terceira, que, como notamos na nota 23 deste trabalho, ainda se encontra inédito.

${ }^{39} \mathrm{O}$ correto mesmo, antes de falar em nó borromeu, é, de fato, cadeia borromeana.

${ }^{40}$ É assim que Lacan situa a vida, no Real. No simbólico está a morte e no imaginário o corpo. Ver A Terceira, inédito.
} 